\title{
ARTIGO CIENTÍFICO \\ Perspectivas de viabilidade econômica e ambiental: Integração entre a piscicultura e fruticultura irrigada em São João do Piauí (PI)
}

\section{Perspectives of economic and environmental viability: Integration between fish farming and irrigated fruit production in São João do Piauí (PI)}

\author{
Maria Keila Jerônimo ${ }^{1}$, Marcelo Batista Gomes ${ }^{2}$, Cláudio Evangelista Sousa ${ }^{3}$, Thiago Oliveira da Silva Brito ${ }^{4}$, Elenice Monte \\ Alvarenga $^{5 *}$
}

\begin{abstract}
Resumo: O Estado do Piauí apresenta-se como excelente campo de trabalho na avaliação da viabilidade de ações que visem à inclusão produtiva, à diversificação da produção e ao aumento da produtividade, permitindo-se, com isso, a avaliação do uso de tecnologias sociais na promoção do desenvolvimento regional sustentável. Neste trabalho objetivou-se atestar a viabilidade econômica e ambiental da utilização das águas do rio Piauí na piscicultura e seu posterior reuso em atividades de irrigação. O município de São João do Piauí no Estado do Piauí se consolida como espaço amostral de grande interesse, pois localiza-se em região semiárida, com sérias dificuldades de infraestrutura e distribuição de renda, além de ser palco para o desenvolvimento de um vultoso projeto de irrigação. Foi realizada uma estimativa do retorno financeiro gerado pela integração entre a piscicultura e a fruticultura irrigada, por meio da coleta de dados demonstrativos do rendimento destas atividades em outros municípios do nordeste do Brasil. Além disso, avaliou-se a viabilidade ambiental do consórcio entre ambos os cultivos, com base no estudo de indicadores de sustentabilidade calculados com dados oriundos de fontes secundárias. A partir das estimativas econômicas realizadas, foi verificada a positividade da viabilidade econômica da associação das cadeias produtivas, bem como se pode notar um maior grau de sustentabilidade ambiental do projeto mediante o consórcio de ambas as atividades produtivas.
\end{abstract}

Palavras-chave: Impacto econômico. Impacto ambiental. Desenvolvimento sustentável.

Abstract: Piauí presents itself as an excellent field of work in assessing the viability of actions that aim at productive inclusion, product diversification and increased productivity leading to the evaluation of the use of social technologies in promoting development sustainable regional. This work seeks to make an economic and environmental feasibility of the use of Piauí river waters in fish farming and its subsequent reuse in irrigation activities. São João do Piauí state Piauí is a sample space of great interest in evaluating the viability of these actions, because it is located in semiarid region with serious problems of infrastructure and income distribution as well as being host to the development of a bulky irrigation project.. An estimation of the financial return generated by the integration between a fish farm and an irrigated fruit tree was carried out, through the collection of data demonstrating the income of these activities in other municipalities in northeastern Brazil. In addition, evaluate the environmental feasibility of the consortium between both crops, based on the study of sustainability indicators calculated with data from secondary sources. From the economic estimates made, an evaluation of the economic feasibility of the association of productive chains was verified, as well as a greater degree of environmental sustainability of the project through the consortium of both productive activities.

Key words: Economic impact. Environmental impact. Environmental development.

\footnotetext{
*Autor para correspondência

Recebido para publicação em 16/11/2015; aprovado em 11/12/2016

${ }^{1}$ Mestrado em Desenvolvimento e Meio Ambiente, Instituto Federal de Educação, Ciência e Tecnologia do Piauí (IFPI), Valença-PI, (86) 99822-9091, keila.jeronimo@ifpi.edu.br.

${ }^{2}$ Mestrado em Políticas Públicas, Instituto Federal de Educação, Ciência e Tecnologia do Piauí (IFPI), marcelo.batista@ifpi.edu.br

${ }^{3}$ Especialização em Metodologia do Ensino em Geografia e História, Instituto Federal de Educação, Ciência e Tecnologia do Piauí (IFPI),

claudio.evangelista@ifpi.edu.br

${ }^{4}$ Mestre em História, Instituto Federal de Educação, Ciência e Tecnologia do Piauí (IFPI), thiagobrito@ifpi.edu.br

${ }^{5}$ Especialista em Gerenciamento de Recursos Ambientais, Instituto Federal de Educação, Ciência e Tecnologia do Piauí (IFPI), elenice.alvarenga@ifpi.edu.br
} 


\section{INTRODUÇÃO}

O estado do Piauí, que ainda persiste como um dos estados mais pobres da federação, apresenta-se como excelente campo de trabalho na avaliação da viabilidade de ações que visem a inclusão produtiva, a diversificação da produção e o aumento da produtividade. Neste sentido, o município de São João do Piauí (PI) se consolida como espaço amostral de grande interesse na avaliação da viabilidade destas ações.

No que se refere às comunidades de assentamentos rurais, tem-se o Assentamento Marrecas como principal exemplo de cadeia produtiva local funcionante, fundamentada em aspectos de natureza ambiental prevalentes. Esta área de assentamento rural, com 10.041 ha de extensão, também dispõe de um importante recurso hídrico que perpassa $6 \mathrm{~km}$ do seu território: trata-se do rio Piauí, que hoje é perene em alguns locais graças à construção da barragem do Jenipapo no município de São João do Piauí (PI). Os assentados contam também com um poço jorrante que apresenta vasão de 180.000 L/hora, utilizado para irrigação de cultivos, abastecimento de uma lavanderia comunitária e de sete chafarizes, para fornecimento de água para os animais. Além desse poço principal, o assentamento conta com mais três jorrantes que são usados para o abastecimento de água das residências do núcleo sede e das agrovilas Capim Grosso e Alto Belo, além de outros poços individuais que são utilizados para o consumo humano, animal e para produção agrícola (NASCIMENTO et al., 2008). No assentamento Marrecas, atualmente estão cadastradas 277 famílias, e as mesmas se distribuem em agrovilas agrupadas em três núcleos: Agrovila I (Núcleo Marrecas Sede), Agrovila II (Núcleo Alto Belo) e Agrovila III (Núcleo Capim Grosso) (NASCIMENTO et al., 2008).

Além da diversidade populacional, sabe-se também que em São João do Piauí (PI), os arranjos produtivos locais concentram-se em atividades de apicultura, caprinocultura e agricultura (SAGI, 2013). No que se refere às atividades agrícolas, há alguns anos foi implantado um projeto piloto de irrigação em cerca de 90 hectares (ha) beneficiando 75 famílias do Assentamento Marrecas. As culturas mais comumente desenvolvidas desde então envolvem a fruticultura, com destaque para o plantio de manga, banana, melão, goiaba e mamão, tendo-se insistido também no cultivo de uvas, dada a existência de condições favoráveis de solo e clima. Em razão do sucesso obtido com tais ações ao longo dos anos, vem sendo instituída recentemente proposta de ampliação das estratégias de irrigação neste assentamento, com vistas ao aumento da produtividade de frutas, que são o maior campo de atuação das famílias assentadas. De acordo com o projeto, há previsão do aumento da área irrigada de 90 para 1000 ha, de modo a se beneficiar cerca de 277 famílias com a possibilidade de cultivo em área privada de 05 ha. (CODEVASF, 2013). Isso se daria por meio da utilização das águas do rio Piauí represadas na barragem do Jenipapo, em um projeto que consumirá alguns milhões de reais e, admitese, apresentará retorno satisfatório, com a geração de empregos diretos e indiretos e a perspectiva de transformação do município de São João do Piauí (PI) em um novo polo de produção de frutas no nordeste. Neste projeto, que inclui a implantação de estações de bombeamento, reservatórios e canais, espera-se poder armazenar água do referido rio em local mais próximo do assentamento, o que poderia, portanto, originar novas oportunidades de utilização desse recurso hídrico.

Tendo em vista o acesso a estratégias de irrigação que têm, cada vez mais, se mostrado útil ao desenvolvimento de culturas variadas no assentamento Marrecas, as famílias assentadas passaram a vislumbrar possibilidades de diversificação de sua produção com vistas ao aumento da renda média anual e ao máximo aproveitamento dos recursos naturais por eles utilizados, posto que, de acordo com estimativas do novo projeto de ampliação de irrigação, cerca de $50 \%$ da capacidade da barragem do Jenipapo passará a ser utilizada nas estratégias de irrigação do assentamento. Com isso, as próprias instituições representantes do assentamento Marrecas, como a APAM (Associação Comunitária do Projeto de Assentamento Marrecas) e a APIM (Associação dos Produtores Irrigantes de Marrecas), em audiência realizada no Instituto Federal de Educação, Ciência e Tecnologia do Piauí (IFPI), apontaram a necessidade da realização de estudos que revelassem a viabilidade da integração das cadeias produtivas da fruticultura irrigada e da piscicultura, com vistas ao reaproveitamento da água utilizada nesta última atividade na condução da primeira, conforme já reportam outros estudos (BAUMGARTNER et al., 2007; AZEVEDO et al., 2007; ALVES et al., 2009; LACERDA et al., 2011)

Assim, neste estudo objetivou-se atestar a viabilidade econômica e ambiental da utilização das águas do rio Piauí represadas na Barragem do Jenipapo em atividade piscicultora e seu posterior reuso em atividades de irrigação integrando-se estas cadeias produtivas.

\section{MATERIAL E MÉTODOS}

\section{Caracterização da área de estudo}

O município localiza-se na microrregião do Alto Médio Canindé, latitude $08^{\circ} 21^{\prime} 29^{\prime \prime}$ e longitude $42^{\circ} 14^{\prime} 48^{\prime \prime}$, apresenta como limites os municípios de Pedro Laurentino e Nova Santa Rita ao norte, João Costa e Coronel José Dias ao sul, Campo Alegre do Fidalgo e Capitão Gervásio Oliveira ao leste e Brejo do Piauí ao oeste. Seu clima é o tropical semiárido quente, apresentando como vegetação predominante a caatinga arbórea e arbustiva (PREFEITURA DE SÃO JOÃO DO PIAUÍ, 2013), cujos solos são de origem sedimentar e altamente arenosos (NASCIMENTO et al., 2008 , p. 21). Além de se localizar em região semiárida, com sérias dificuldades de infraestrutura e distribuição de renda, o município apresenta em seu conjunto populacional especificidades que enriquecem um trabalho de pesquisa ali realizado. Isto porque, além da população urbana, neste município também há comunidades em assentamentos rurais (São José, Estação, Lisboa e Marrecas) e comunidades tradicionais quilombolas

\section{Estimativa de retorno financeiro da associação entre piscicultura e fruticultura irrigada}

Com vistas a se atestar a viabilidade econômica da integração entre as cadeias produtivas da piscicultura e da fruticultura irrigada foram utilizados dados de fontes secundárias, uma vez que o empreendimento ainda não está implantado em sua totalidade. Para o desenvolvimento da análise da viabilidade econômica da piscicultura foi padronizada a estimativa do investimento do projeto para um hectare de lâmina d'água ou $10.000 \mathrm{~m} 2$, tendo sido a tilápia 
(Oreochromis niloticus) a espécie de peixe elencada para o cultivo, dada sua ampla utilização em atividades piscicultoras, principalmente na região nordeste, e o fato de adaptar-se bem a qualquer ambiente, sendo, inclusive, considerada a "galinha" das águas, por sua ampla distribuição. Acredita-se que a escolha desta espécie não representa risco ambiental, porque os reservatórios previstos no projeto não apresentarão ligação direta com os corpos d'água naturais. Já para a análise da viabilidade econômica da fruticultura foi padronizada a estimativa do investimento do projeto para um hectare de cultivo de uva, que, conforme mencionado, constitui-se em uma das principais espécies frutíferas cultivadas atualmente no assentamento. Neste sentido, por meio da construção de fluxo de caixa simplificado do consórcio de ambas as atividades econômicas (fruticultura e piscicultura), foi realizada a análise de indicador de rentabilidade do projeto (valor presente líquido - VPL), bem como de indicador associado ao risco do projeto (taxa interna de retorno - TIR).

\section{Análise dos impactos ambientais gerados pela integração entre piscicultura e fruticultura irrigada}

A contabilidade ambiental realizada com o uso da estratégia emergética se utiliza dos conceitos da Termodinâmica de Sistemas Abertos e da Teoria de Sistemas, que, da Física, faz referência a todos os processos que envolvem todas as formas de energia e materiais existentes. Nesse sentido, a emergia se caracteriza como estratégia que permite a avaliação e/ou mensuração das implicações ambientais decorrentes da ação de sistemas humanos sobre os ecossistemas naturais. Tal metodologia centrada em comparativos de consumo e produção energéticos necessita da determinação de uma unidade de medida comum que permita a análise de ecossistemas naturais, a que convencionou-se utilizar a energia solar.

Deste modo, a fim de se prosseguir com o propósito comparativo, todas as formas de energia presentes no ecossistema analisado são inseridas em termos da energia solar equivalente. Para se chegar ao valor da energia solar equivalente de um dado recurso, será estabelecido um fluxograma completo, envolvendo entradas e saídas de energia, bem como o processo de transformação de energia que ocorre sucessivamente em um ecossistema. Após o estabelecimento do fluxograma, com a integração de todos os processos que o permeiam, devem ser obtidos os valores de transformidade dos respectivos processos, o que nos conduzirá ao conceito de emergia. A somatória das emergias envolvidas no sistema avaliado fornecerá o valor da emergia necessária para produzir certa quantidade de um recurso. Assim, no valor de emergia encontra-se embutida a valoração dos "serviços prestados" pela natureza que, geralmente, não são apresentados em função de seu custo monetário, uma vez que estão fora do marco de referência da metodologia econômica convencional. Daí a relevância da apresentação de estudos de viabilidade ambiental em consonância com estudos de viabilidade econômica (ODUM, 1996).

\section{RESULTADOS E DISCUSSÃO}

Estimativa de retorno financeiro da associação entre piscicultura e fruticultura irrigada

De acordo com dados apresentados pela Cartilha do Pescador e Aquicultor, um bom modelo de produção para a região Nordeste do país pode ser o da criação de tilápias
(Oreochromis niloticus). Neste modelo, em um reservatório 0,25 ha ou $2.500 \mathrm{~m} 2$ é possível produzir 2,5 toneladas de peixes por ciclo de seis meses. Com a comercialização do pescado a $\mathrm{R} \$ 5,00$ o quilo, é estimada uma renda bruta mensal de cerca de R \$ 2.000,00 (NOVAES et al., 2012; MPA, 2014). Adaptando-se tais valores à realidade do caso aqui estudado, prevê-se, a cada hectare de lâmina d'água cultivado, a produção de 10 toneladas de peixes por cada ciclo (seis meses), estimando-se uma renda bruta mensal de aproximadamente $\mathrm{R} \$ 8.300,00$, aproximadamente $\mathrm{R} \$$ 100.000,00 anuais. Considerando-se o percentual inflacionário para os anos seguintes, foram calculados valores aproximados de receita anual também para um período futuro.

Considerando-se a já implantada produção de uvas no assentamento em São João do Piauí (PI) e admitindo-se como sendo de 15 toneladas/ano (BEZERRA, 2007) a produtividade média da área, pode-se supor que, com a ampliação da mesma para 1000 ha, haveria um aumento na produção média de uvas para aproximadamente 166 toneladas/ano. Para fins de cálculo da renda bruta anual com a comercialização das uvas, assumiu-se o valor médio de $\mathrm{R} \$$ $2,50 / \mathrm{kg}$ de frutas, chegando-se a um valor médio de renda bruta anual de $\mathrm{R} \$ 415.000,00$.

Para os cálculos consideraram-se também valores médios de custos observados em outros empreendimentos, no que se refere às contas coletivas, manutenção de equipamentos e veículos e outras despesas relacionadas a ambas as atividades de cultivo (CODEVASF, 2008).

Então, considerando-se a estimativa de custos e de receitas da produção de tilápia no nordeste apresentada pela Cartilha do Pescador e Aquicultor (SAMPAIO; BRAGA, 2005; MPA, 2014) e a estimativa de receitas da produção de frutas também no assentamento (BEZERRA, 2007), foi produzido o fluxo de caixa simplificado, comum às duas atividades produtivas. Para isso, padronizaram-se as taxas de juros sobre o capital operacional e sobre o investimento em 5\% a.a. (MPA, 2014; CODEVASF, 2008), considerado um valor mediano de taxas de juros utilizado em programas de fortalecimento da agricultura familiar e da piscicultura pelo Governo Federal.

Considerando-se que alguns custos sejam comuns à realização de ambas as atividades e dado o fato da reutilização da água, que concorreria, principalmente, na economicidade dos recursos ambientais, pode-se perceber que, de um modo geral, a renda média anual dos produtores seria aumentada com a realização das atividades de fruticultura em associação à piscicultura, o que contribuiria para a geração de riquezas a nível local, promovendo o desenvolvimento econômico de São João do Piauí (PI).

No que se refere aos indicadores econômicos de rentabilidade do projeto (valor presente líquido - VPL), e de risco do projeto (taxa interna de retorno - TIR), entretanto, percebe-se que, diante de um VPL de R\$ 2.501,13, embora exista ganho financeiro, este valor presente do referido fluxo de caixa mostra-se relativamente baixo, principalmente, se considerarmos os recursos ambientais que serão utilizados no desenvolvimento de ambas as atividades econômicas. Este dado é corroborado pela TIR de apenas 4,84\%. Contudo, ao se considerar outros fatores, como a ausência de infraestrutura local e de recursos para o desenvolvimento de atividades econômicas mais rentáveis, bem como as intempéries locais que dificultam as ações de produção agrícola e pecuária, o 
ganho financeiro representado pelo consórcio de ambas as atividades produtivas ainda assim é relevante.

Análise dos impactos ambientais gerados pela integração entre piscicultura e fruticultura irrigada

O processo de instituição do Assentamento Marrecas em São João do Piauí (PI) remonta a 1989, quando cerca de 100 famílias provenientes deste e de outros municípios da região semiárida piauiense, como Paulistana, Simões, Pio IX e Picos, instalaram-se nesta região em uma fazenda, supostamente improdutiva, que levava o mesmo nome (NASCIMENTO, 2008). Este representou o primeiro processo de ocupação de terras coordenado pelo MST no estado do Piauí, daí sua relevância e papel de destaque nas rememorações sobre o tema. O Assentamento Marrecas, entretanto, só foi oficialmente criado em 1994 por meio de portaria específica do Instituto Nacional de Colonização e Reforma Agrária (Incra), que definiria processo de posse das terras por meio de regime de compra e venda de cerca de 10000 hectares localizados às margens do Rio Piauí (GONÇALVES, 2009). Atualmente, as famílias assentadas no Marrecas encontram-se distribuídas em regiões do assentamento, relativamente bem delimitadas por alguns marcadores limítrofes, como a rodovia, lagoas e áreas de cultivo. Tais regiões são as três agrovilas nas quais se estabelece o assentamento: núcleo Marrecas Sede, núcleo Alto Belo e núcleo Capim Grosso.

Para melhor compreensão do movimento de expansão da área irrigada, cabe retomar o aspecto histórico da estruturação do assentamento. Há alguns anos, o poder público vem desenvolvendo ações de implantação de projeto piloto de irrigação em assentamentos rurais em São João do Piauí (PI). Consoante a isso, no Assentamento Marrecas foi implantado um projeto piloto de irrigação em 90 ha., beneficiando 75 famílias. As culturas mais comumente desenvolvidas desde então envolvem a fruticultura, com destaque para o plantio de manga, banana, melão, goiaba e mamão, tendo-se insistido também no cultivo de uvas, dada a existência de condições favoráveis de solo e clima. É válido ainda ressaltar que muitas famílias, embora residentes no Assentamento Marrecas, acabaram por não se envolver nas estratégias de cultivo irrigado, mantendo-se dependentes do regime de chuvas (cultivo de sequeiro), bastante escassas nessa região ao longo do ano. Em razão do sucesso obtido com tais ações ao longo dos anos, instituiu-se recentemente uma proposta de ampliação das estratégias de irrigação nestes assentamentos com vistas ao aumento da produtividade de frutas, maior filão de atuação das famílias assentadas que investiram nos procedimentos de irrigação da produção. No Assentamento Marrecas, mais especificamente, planeja-se essa ampliação com a utilização de recursos da União oriundos do Programa de Aceleração do Crescimento (PAC), objetivando o aumento da área irrigada de 90 para 1000 ha., considerando-se o uso de água da Barragem do Jenipapo também localizada no município de São João do Piauí (PI), originando o chamado Perímetro de Irrigação Marrecas-Jenipapo. Com este projeto, cerca de 200 famílias passariam a ser beneficiadas, com a possibilidade de cultivo em lotes privados de 05 ha, geração de empregos diretos e indiretos e aumento da produtividade (CODEVASF, 2013). Segundo estudo realizado pela CODEVASF (CODEVASF, 2013) a ampliação da área irrigada no Assentamento Marrecas possibilitaria a criação de cerca de 191.800 empregos temporários por ano, mais 1.000 empregos indiretos e 200 empregos diretos decorrentes do assentamento das famílias nos lotes. Admite-se, ainda, segundo informações previstas no mesmo documento oficial, que a implantação deste novo modelo agrícola para a região acarretaria um aumento de mais de $80 \%$ na renda média da população no município de São João do Piauí (PI), elevandose de $\mathrm{R} \$$ 822,06 (CODEVASF, 2013) para $\mathrm{R} \$ 5.427,57$.

Gradativamente, desde o início de sua estruturação enquanto assentamento, no Marrecas os produtores passaram a organizar-se em esquema de cooperativa e, atualmente, já dispõem, inclusive, de indústria para beneficiamento da produção e fabricação de polpa de frutas, geleias e doces. Este fato mostra-se relevante porque passou a criar estratégias de inserção das mulheres residentes nas agrovilas no processo produtivo e de geração de renda.

Sabidamente, esse processo de inclusão feminina traz diversas consequências positivas, não apenas do ponto de vista financeiro, mas também da valorização da força de trabalho feminina, que passou, inclusive, a expor-se a condições menos degradantes de trabalho, uma vez que substituíram as atividades de cultivo no campo por atuação em ambiente fechado na indústria de beneficiamento da produção.

Tendo em vista o histórico que traduz a produção no âmbito do assentamento, o diagrama abaixo (Figura 1), que representa todos os fluxos energéticos de entrada no sistema de cultivo de frutíferas, bem como os fluxos internos de energia que supostamente ocorrem na atividade produtora de frutas no Assentamento Marrecas.

$\mathrm{Na}$ figura 2 tem-se representados os fluxos energéticos de entrada na atividade piscicultora. Para o estabelecimento destes fluxos, considerou-se a atividade de criação de tilápias em tanques-rede, inicialmente, por tratar-se de espécie de cultivo mais comum na região e também por representar método de relativo fácil manejo. Hipoteticamente, considerando-se a proporção das áreas de reserva de água próximas ao assentamento Marrecas, poder-se-ia instituir áreas de cultivo de peixes dentro de reservatórios existentes, que apresentam as seguintes características: área de 182,94 ha, vazão de água de $1,23 \mathrm{~m} 3 / \mathrm{s}$, profundidade de $7 \mathrm{~m}$, com entradas de peixes ocorrendo semanalmente em tanques-rede de até $6 \mathrm{~m} 3$, onde permanecerão por cerca de 4 meses até atingir massa média de cerca de $450 \mathrm{~g}$, considerando-se que a quantidade de peixe anual sobrevivente é de 100000. 
Figura 1. Diagrama simplificado de fluxos de energia para o cultivo de plantas frutíferas.

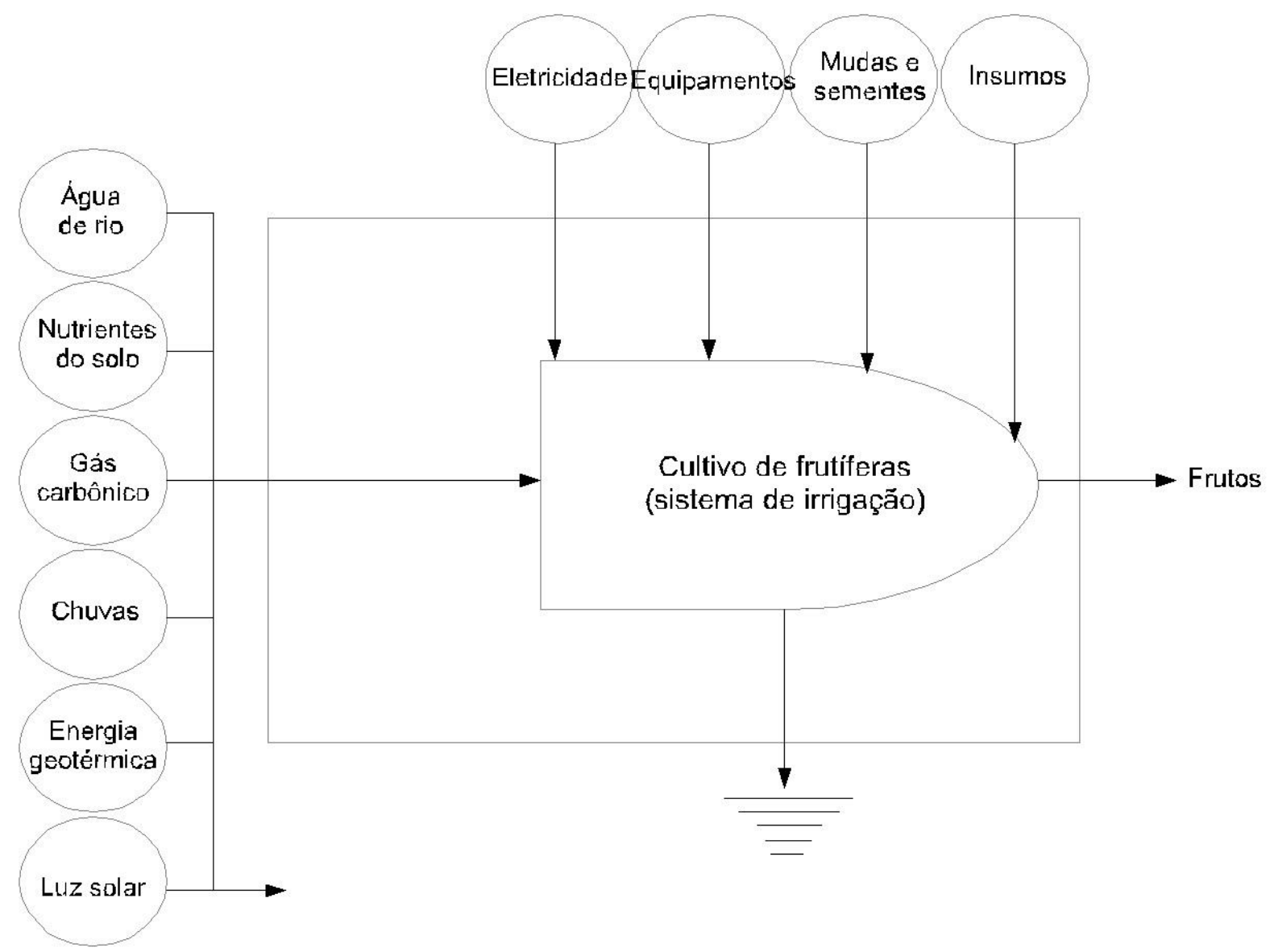

Fonte: Autor (2016)

Assim, as entradas a que se referem a criação de peixes neste sistema representado na Figura 2 são: as renováveis (energia solar, energia química da chuva, energia potencial da água, água de rio, oxigênio, alimento natural), as não renováveis (perda de biodiversidade) e as pagas (mão de obra, maquinário, bombas e motores, aço, concreto, madeira, metais, plástico, cimento, amianto); considerando-se que o limite temporal para a análise será de um ano (PIEROBOM, 2009).

Tendo em vista a necessidade de simplificação dos processos de análise de custo ambiental aqui realizada, algumas das entradas energéticas supracitadas foram desconsideradas, uma vez que não interfeririam sobremaneira no resultado da análise.

Após a realização de cálculos quantitativos de cada item apresentado nos diagramas e, posteriormente, com a realização de cálculos referentes à emergia, foi possível perceber que os indicadores de sustentabilidade para a atividade de cultivo de plantas frutíferas individualmente são relativamente menores, se comparados aos indicadores de sustentabilidade de ambas as atividades, cultivo de frutíferas e atividade piscicultora, consorciadas. Tal fato permite inferir que houve o emprego de recursos naturais de modo mais eficiente com o consórcio das atividades, uma vez que permitiu uma maior produção mediante menor emergia

Confirmou-se, a partir das estimativas econômicas realizadas, a positividade da viabilidade econômica da associação das cadeias produtivas, bem como se pode estabelecer um panorama geral da sustentabilidade ambiental do projeto.

É sabido que atualmente no Brasil existe necessidade cada vez maior de produção de alimentos, principalmente para consumo em regiões mais isoladas e que não dispõe de mecanismos de acesso facilitado à produção em outros locais. Com isso, a implantação de estratégias que tragam a municípios como São João do Piauí (PI), com sérias dificuldades de ordem climática e ambiental que afetam a produção agrícola, a possibilidade de plantio de culturas variadas nas mais distintas épocas do ano torna-se bastante atraente. Neste sentido, concluiu-se que a integração entre estas duas atividades produtivas representará aumento da acessibilidade dos processos, já que ampliam a atuação das famílias assentadas na economia local e regional, gerando mais renda e constituindo-se como oportunidade de inclusão produtiva.

A integração de cadeias produtivas no campo tem impactos positivos na vida rural, pois na medida em que se diversificam a produção no campo, promove-se também, uma diversificação e expansão da atividade econômica, a partir das potencialidades regionais, estimulando a realização de novos e inovadores empreendimentos. Tais ações irão refletir na fixação da população no campo, diminuindo as constantes migrações de jovens que se aventuram nos grandes centros urbanos em busca de emprego e melhores salários. 
Figura 2. Diagrama simplificado de fluxos de energia para criação de peixes em sistema de tanques-rede.

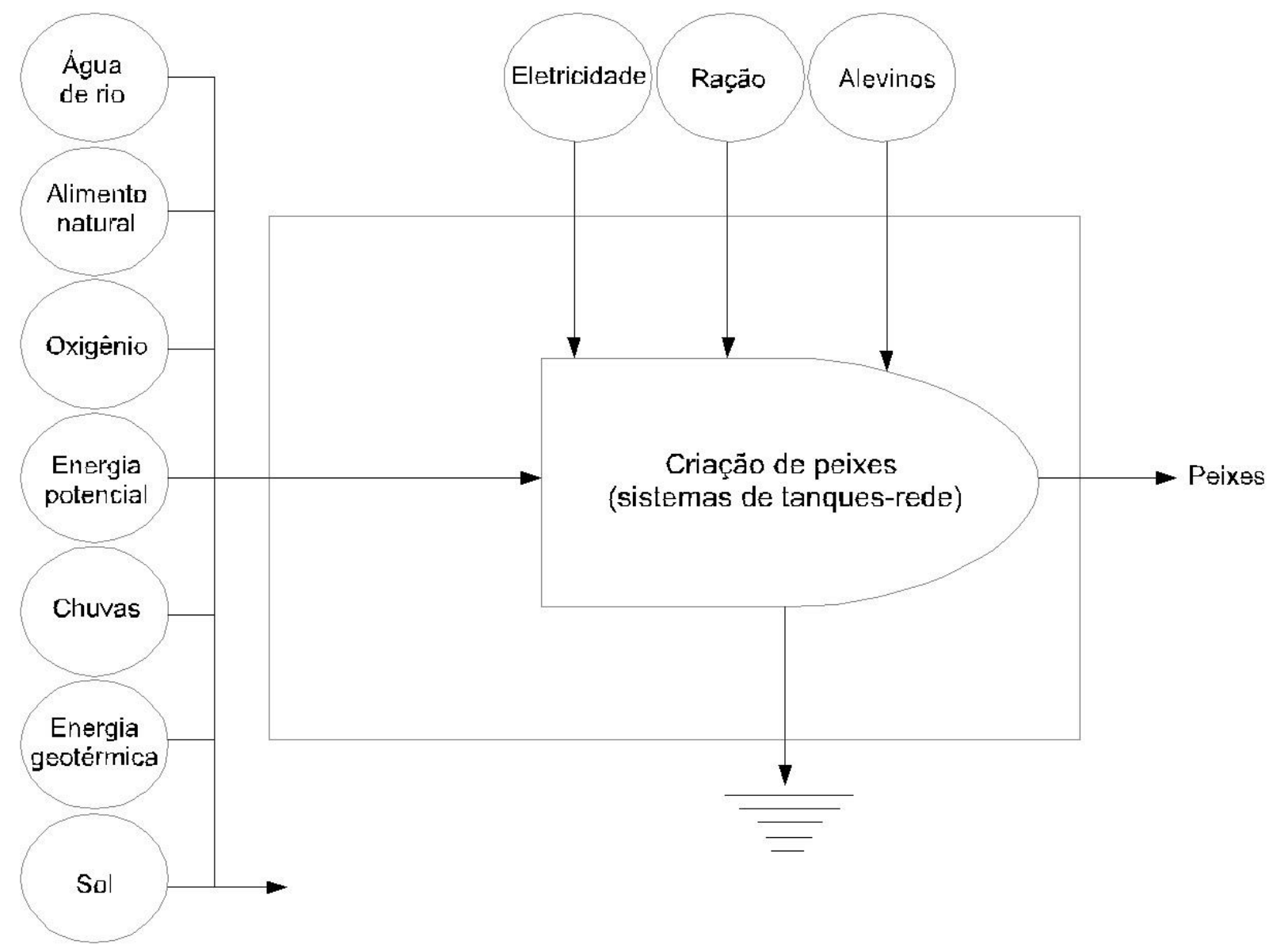

Fonte: Adaptado de Pierobom (2009).

Estudos dessa natureza também se mostram relevantes no contexto produtivo em São João do Piauí (PI), pois servem ao embasamento de ações para fortalecimento dos arranjos produtivos locais, objetivando o aumento da produtividade no cultivo irrigado de frutas integrado à piscicultura, com o reaproveitamento das águas, o que geraria, inclusive, economia dos recursos naturais. Além disso, é importante mencionar que estudos que contribuam para a promoção de atividades dessa natureza consistem de típico exemplo de emprego de tecnologia social que, solucionando em parte o problema da distribuição de renda, atenderia a quesitos como a simplicidade, baixo custo, fácil aplicabilidade e impacto social comprovado.

Um perpasso histórico nos remete ao fato de que, de modo geral, se costumava realizar o cultivo de mais de um produto. Entretanto, com a evolução temporal, o aumento na demanda por alimentos e a evolução de aspectos tecnológicos que favoreceram a otimização da produção, estes fatores conduziram a uma situação de especialização na produção e nos cultivos, caracterizando-se a agricultura moderna enquanto sistema padronizado e simplificado de monocultura. Além disso, é possível também perceber, ao longo do tempo, um processo de expansão das fronteiras agrícolas, alto padrão de mecanização, e aumento da utilização de agroquímicos, o que favoreceu ainda mais o processo de dissociação e independência dos cultivos. Entretanto, como todo modelo exaustivamente aplicado, este se encontra em processo de saturação, em função da grande demanda por recursos renováveis ou não, o que vem contribuindo para o retorno de práticas de cultivo associadas a outras cadeias produtivas (BALBINO et al., 2011)

Assim, pelo prisma das análises econômicas é fundamental que se realizem estudos que descrevam e demonstrem as potenciais vantagens de sistemas de produção consorciados, uma vez que estes apresentam grande valia, por exemplo, no processo de minimização de emissões de carbono, maior eficiência no consumo de recursos renováveis ou não, bem como no uso de insumos, o que se reflete em vultosos ganhos econômicos (MARTHA JÚNIOR et al., 2011). Deste modo, cabe aos gestores elaborarem suas diretrizes governamentais, visando promover a melhoria da qualidade de vida da população, a distribuição equitativa da riqueza produzida, o desenvolvimento social e econômico, através da utilização racional dos recursos naturais e sem degradação do meio ambiente.

\section{CONCLUSÕES}

Os indicadores econômicos de rentabilidade do projeto mostram que o ganho financeiro representado pelo consórcio de ambas as atividades produtivas é relevante, mesmo com valor presente do referido fluxo de caixa relativamente baixo.

Os indicadores de sustentabilidade, apontam o emprego de recursos naturais de modo mais eficiente com o consórcio das duas atividades.

Confirmou-se a positividade da viabilidade econômica da associação das cadeias produtivas, bem como se pode 
estabelecer um panorama geral da sustentabilidade ambiental do projeto.

\section{AGRADECIMENTOS}

Este trabalho foi financiado pelo Conselho Nacional de Desenvolvimento Científico e Tecnológico (CNPq, Processo no 488123/2013-5). Agradecemos também à Profa. Dra. Jaíra Maria Alcobaça Gomes (UFPI) pelas contribuições no processo de análise econômica.

\section{REFERÊNCIAS}

ALVES, W. W. A.; AZEVEDO, C. A. V.; DANTAS NETO, J.; LIMA, V. L. A.; SOUSA, J. S. C. Altura da planta do algodoeiro de fibra marrom irrigado com água residuária doméstica tratada. Revista Verde de Agroecologia e Desenvolvimento Sustentável, Pombal, v.4, n.1, p.28-32, 2009.

AZEVEDO, M. R. Q. A.; KÖNIG, A.; BELTRÃO, N.E.M.; AZEVEDO, C. A. V.; TAVARES, T. L.; SOARES, F. A. L. Efeito da irrigação com água residuária tratada sobre a produção de milho forrageiro. Revista Brasileira de Ciências Agrárias, Recife, v.2, n.1, p.63-68, 2007.

BALBINO, L. C.; CORDEIRO, L. A. M.; PORFIRIO-DASILVA, V.; MORAES, A.; MARTÍNEZ, G. B.; ALVARENGA, R. C.; KICHEL, A. N.; FONTANELI, R. S.; SANTOS, H. P.; FRANCHINI, J. C.; GALERANI, P. R. Evolução tecnológica e arranjos produtivos de sistemas de integração lavoura-pecuária-floresta no Brasil. Pesquisa Agropecuária Brasileira, Brasília, v.46, n.10, p.i-xii, 2011.

BAUMGARTNER, D.; SAMPAIO, S. C.; SILVA, T. R.; TEO, C. R. P. A.; VILAS BOAS, M. A. Reúso de águas residuárias da piscicultura e da suinocultura na irrigação da cultura da alface. Engenharia Agrícola, Jaboticabal, v.27, n.1, p.152-163, 2007.

CODEVASF, COMPANHIA DE DESENVOLVIMENTO DOS VALES DO SÃO FRANCISCO E DO PARNAÍBA. Centro de Conhecimento em Agronegócios (PENSA). Projeto integrado de negócios sustentáveis - PINS: cadeia produtiva de piscicultura. Brasília: CODEVASF, 2008.

CODEVASF, COMPANHIA DE DESENVOLVIMENTO DOS VALES DO SÃO FRANCISCO E DO PARNAÍBA. Projeto de irrigação Marrecas-Jenipapo (PI) recebe visita do ministro da Integração Nacional. Disponível em: $<$ http://www.codevasf.gov.br/noticias/2007/projeto-deirrigacao-marrecas-jenipapo-pi-recebe-visita-do-ministro-daintegracao-nacional>. Acesso em: 06/11/2013.

GONÇALVES, M. C. Juventudes do campo e práticas educativas: o caso do Assentamento Marrecas em São João do Piauí-PI. 2009. 160f. Dissertação (Mestrado em Educação) - Universidade Federal do Piauí, Teresina. 2009.
LACERDA, P. M.; RODRIGUES, R. F.; NALINI JÚNIOR, H. A.; MALAFAIA, G.; RODRIGUES, A. S. L. Influência da irrigação com águas residuárias no desenvolvimento de feijão-de-porco (Canavalia ensiformis). Revista Acadêmica: Ciências Agrárias e Ambientais, Curitiba, v.9, n.2, p.159-168, 2011.

MARTHA-JÚNIOR, G. B.; ALVES, E.; CONTINI, E. Dimensão econômica de sistemas de integração lavourapecuária. Pesquisa Agropecuária Brasileira, Brasília, v.46, n.10, p. 1117-1126, 2011.

MINISTÉRIO DA PESCA E AQUICULTURA (MPA). Plano Safra da Pesca e Aquicultura 2012/2013/2014. Disponível em: <www.asbraer.org.br/arquivos/bibl/89-planosafra-pesca-aquicultura.pdf $>$. Acesso em: 13/02/2014.

NASCIMENTO, H. T. S.; LUZ, K. S.; WOLFF, L. F.; NASCIMENTO, M. P. S. C. B.; OLIVEIRA, M. E. Plantas do Semi-Árido: conhecimento e usos no Assentamento Marrecas. Teresina: Embrapa Meio-Norte, 2008. p. 21-23.

NOVAES, A. F.; PEREIRA, G. T.; MARTINS, M. I. E. G. Indicadores zootécnicos e econômicos da tilapicultura em tanques-rede de diferentes dimensões. Boletim do Instituto de Pesca, São Paulo, v.38, n.4, p. 379-387, 2012.

ODUM, H. T. Environmental accounting. Emergy and environmental decision making. New York: John Wiley and Sons, 1996.

PIEROBOM, J. L. Estudo da sustentabilidade ambiental em diferentes sistemas de criação de tilápias. 2009. $120 f$. Dissertação (Mestrado em Engenharia de Produção) Universidade Paulista, São Paulo. 2009.

PREFEITURA DE SÃO JOÃO DO PIAUÍ. Informações gerais. Disponível em: <http://www.saojoaodopiaui.pi.gov.br/municipio/>. Acesso em: 10/10/2013.

BEZERRA, J. A. Uvas Assentadas. Revista Globo Rural, Rio de Janeiro, ed. 261, p. 69-71, 2007.

SAGI, SECRETARIA DE AVALIAÇÃO E GESTÃO DA INFORMAÇÃO. Relatório de Informações Sociais. Disponível em: <aplicacoes.mds.gov.br/sagi/RIv3/geral/index.php>. Acesso em: 10/10/2013.

SAMPAIO, J. M. C.; BRAGA, L. G. T. Cultivo de tilápia em tanques-rede na barragem do Ribeirão de Saloméa - Floresta Azul - Bahia. Revista Brasileira Saúde Produção Animal. v.6, n.2, p. 42-52, 2005. 